\title{
Child Sexual Abuse in Puttalam, Sri Lanka: a medico-legal analysis
}

\author{
Amararatne RRGS $S^{1}$, Vidanapathirana $M^{2}$
}

\begin{abstract}
Introduction: All cases of child sexual abuse (CSA) are expected to be examined by specialists in Forensic Medicine in Sri Lanka. Further, management should not be confined to medico-legal aspects but ensure the psychosocial management of child and family. Therefore, this study was conducted to identify and describe patterns of abuse and strategies of management of children affected with CSA. Methods: Retrospective descriptive study was conducted on all the victims of child sexual abuse reported to Base Hospital, Puttalam, Sri Lanka over 20 months from Nov-2014 to June-2016. Results: There were 183 children affected and of them, 168 (92\%) were girls. Out of incidents occurred at home, $52 \%$ were committed by relatives $(\mathrm{p}=0.000)$. All abusers were male and none were strangers. Known non-relatives abused $64 \%$ of females and almost all male victims $(\mathrm{p}=0.02)$. In more than 10 years old female victims, $80 \%$ had hymenal tears $(\mathrm{p}=0.000)$. One-third of both males and females had anal penetration. Only five (05) had associated physical abuse. Eighty percent were referred to STI and $84 \%$ to psychiatrist. Institutional case conference was held in $20 \%$. It was held in $8 \%$ of anal and $20 \%$ of genital penetrations $(\mathrm{p}=0.8)$.Conclusions: Physical abuse was rarely associated with child sexual abuse. Majority of incidents were committed by male relatives. Known non-relatives are the most potential abusers. Girls more than 10 years are the most vulnerable for penetration. None were given STI prophylactic treatment. Mere presence of injuries were not indications for case conference. However, the follow-up reports of psycho-social managements were not available.
\end{abstract}

Key words: child sexual abuse, Puttalam, Sri Lanka,

\section{Full paper}

\section{Introduction}

Patterns of child sexual abuse (CSA) are different from country to country and also from area to area within a country. Once in every two minutes someone in the United States is sexually assaulted. ${ }^{[1]}$ According to police statistics, incidents of sexual abuse has been increasing in Sri Lanka. ${ }^{[2]}$ Sexual abuse of children is not uncommon in the society, however, it is not always recognized or reported. Identifying the actual number of abused children is a challenge because reporting of such incidents to police or authorities is highly variable and the prevalence of reporting of such data across the studies is also largely variable. [3]

1Consultant Judicial Medical Officer, Base Hospital, Puttalam, Sri Lanka, 2Professor of Forensic Medicine, Department of Forensic Medicine, Faculty of Medical Sciences, University of Sri Jayewardenepura, Sri Lanka

Corresponding author: Vidanapathirana M, Email: mudithavidana@sjp.ac.lk, Tel: 0094772988227

http://orcid.org/0000-0003-0071-0996

DOI: http://doi.org/10.4038/mljsl.v4i2.7336
All cases of child sexual abuse are expected to be examined by specialists in Forensic Medicine in Sri Lanka. Further, the management of child sexual abuse should not be confined to medico-legal aspects but ensure psycho-social management of child and family as a whole. Therefore, this study was conducted to identify and describe the patterns of CSA and management strategies in Puttalam, Sri Lanka.

\section{Study design and methodology}

A retrospective descriptive cross-sectional study was conducted on the reported children of child sexual abuse (CSA) to the Base Hospital, Puttalam, Sri Lanka over 20 months from November 2014 to June 2016. Out of 16 police areas of Puttalam District, all the sexual abuse cases of 10 police areas are now produced to the Base Hospital, Puttalam. All medico-legal examination forms (MLEFs) of four Forensic Medical Officers were perused to identify the affected children of CSA.

In this study, the level of education was classified as up to grade 5, from grade 6- 11 and up to Advanced Level. 
The location of the incident was classified as home or outside. In this study, the perpetrators were classified as relatives, non-relatives and unknown (strangers).

Demographic factors, factors related to the incidents, the abusers correlates, injuries sustained, and the management strategies were studied.

The hymenal injuries were classified as complete tears, partial tears, notches and attenuated hymen. When the hymenal tear reaches the wall of the vagina, it was considered as complete and partial when it does not reach. When the partial tear involves only the margin of the hymen, it was considered as a notch. The anterior notches were excluded. When the hymen was worn off and limited only to the rim of the vagina, it was considered as attenuated.

IBM-SPSS statistical package 19.0 was used in the analysis of data. Chi-square tests were performed in bivariate tests, and $\mathrm{P}<0.05$ were considered statistically significant. Since it is a clinical audit on already available data, the permission of the Director of the hospital was obtained prior to the study.
Analyzing data from MLEFs/ BHTs have limitations such as non-availability of all required information and the experience of the examiner would determine the outcome of the findings.

\section{Results}

There were 183 victims of Child sexual abuse (CSA) reported and $92 \% \quad(n=168)$ were girls and the remaining victims were males. The distribution of victims according to their sex is shown in Table 1. Ages ranged from 3-18 years and mean age was 12.65 years with SD+/- 3.462. Of them, 67\% $(n=123)$ belonged to $11-15$ years and $77 \%(n=141)$ were above 10 years (11-18 years). The distribution of age is shown in Table 1.

There were victims of all three races; Sinhala, Muslim and Tamil. Of them, 90\% $(n=164)$ Sinhalese and the distribution of the races are shown in Table 1. At the time of the incident, $69 \%(n=127)$ had studied up to $11^{\text {th }}$ grade and the educational level of the victims are illustrated in Table 1.

\section{Table 1: Demographic data}

\begin{tabular}{lll}
\hline \hline & Socio-demographic factors & $\begin{array}{l}\text { Total }(\mathbf{N}=183) \\
\%(\mathbf{n})\end{array}$ \\
\hline Sex & Female & $92(168)$ \\
& Male & $08(15)$ \\
& & \\
Age & $00-05$ & $05(10)$ \\
& $06-10$ & $18(32)$ \\
& $11-15$ & $67(123)$ \\
& $16-18$ & $10(18)$ \\
Race & Sinhala & $90(164)$ \\
& Muslim & $09(16)$ \\
& Tamil & $01(03)$ \\
Education level & Up to $5^{\text {th }}$ grade & $29(53)$ \\
& $6^{\text {th }}$ to $11^{\text {th }}$ grade & $69(127)$ \\
& Advanced level & $02(03)$ \\
\hline \hline
\end{tabular}

Fifty three percent $(n=96)$ incidents had taken place at home and the remaining incidents at places outside home. The distribution of the place of occurrence is shown in Table 2. 
All the abusers were male. When the type of abuser was considered, $66 \%(n=121)$ were non-relatives and the remaining abusers were relatives. Out of 15 male victims almost all $(n=14)$ were abused by nonrelatives. Abuser was the father in one instance. The type of abusers are shown in Table 2.
In $52 \%(n=50)$ of incidents occurred at home and $14 \%$ $(n=12)$ of incidents occurred outside were committed by relatives and this difference was significant $(\mathrm{x} 2=29.87, \mathrm{df}=1, \mathrm{p}=0.000)$ But the place of occurrence whether at home or outside, was not significantly associated with urban or rural living $(\mathrm{p}=0.317)$.

Table 2. Distribution of the factors related to the incident

\begin{tabular}{|c|c|c|}
\hline & Factors related to incident & $\begin{array}{l}\text { Total }(\mathrm{N}=183) \\
\%(\mathrm{n})\end{array}$ \\
\hline \multirow[t]{2}{*}{ Site } & Home & $53(97)$ \\
\hline & Outside & $47(86)$ \\
\hline \multirow[t]{3}{*}{ Abuser } & Relatives & $34(62)$ \\
\hline & Known-Non-relatives & $66(121)$ \\
\hline & Unknown(Strangers) & $00(00)$ \\
\hline
\end{tabular}

When the genital findings of the girls were considered $(n=168)$, the types of hymens found were cresentic, annular, fimbriated and attenuated. Among girls, 56\% $(n=94)$ had cresentic hymen and the distribution of the hymen types are shown in Table 3 . Among less than 10 years girls, most $(91 \%, n=32)$ had cresentic hymens. In $82 \%(n=28)$ of less than 10 years of age and $50 \%(n=66)$ of over 10 years of age had cresentic hymens and this difference was significant $(\mathrm{x} 2=11.256, \mathrm{df}=1, \mathrm{p}=0.001)$.

Except for one instance, all others had healed old injuries in the hymen. The type of injuries found in the hymen were complete tears, partial tears, notches and attenuation. Among girls, 44\% $(\mathrm{n}=74)$ had complete tears and $27 \%(n=45)$ had no hymenal tears. The distribution of the hymenal tears are show in Table 3. Out of complete and partial tears, three (03) were in the anterior half of the hymen and the remaining were posterior half tears. In $45 \%(n=16)$ of less than 10 years of age and $80 \%(n=107)$ of more than 10 years of age had tears and this difference was significant $(\mathrm{x} 2=17.049, \mathrm{df}=1, \mathrm{p}=0.000)$. Both home $(73 \%, \mathrm{n}=66)$ and outside $(73 \%, \mathrm{n}=57)$ incidents caused tears in hymen. 
Table 3. Analysis of the genital findings of girls

\begin{tabular}{|c|c|c|}
\hline & Findings and injuries & $\begin{array}{l}\text { Total }(\mathrm{N}=168) \\
\%(\mathrm{n})\end{array}$ \\
\hline \multirow[t]{4}{*}{ Type of hymen } & Cresentic & $56(94)$ \\
\hline & Annular & $21(35)$ \\
\hline & Fimbriated & $21(35)$ \\
\hline & Attenuated & $02(04)$ \\
\hline \multirow[t]{5}{*}{ Hymenal tears } & Complete & $44(74)$ \\
\hline & Partial & $24(40)$ \\
\hline & Posterior Notches & $03(05)$ \\
\hline & Attenuated & $02(04)$ \\
\hline & No tears & $27(45)$ \\
\hline
\end{tabular}

When considered the males $(n=15), 33 \% \quad(n=05)$ showed evidence of anal penetration and other $67 \%$ $(n=10)$ did not show any genital or anal injuries. Among female victims 58 had evidence of anal penetration. When the type of penetration was analyzed considering both male and female victims, $50 \%(n=92)$ had evidence of vaginal penetration, $7 \%$ $(n=12)$ had evidence of anal penetration and the distribution of penetration is shown in Table 4. Three female victims were pregnant. In $33 \%(n=5)$ of males and $34 \%(n=58)$ of females had evidence of anal penetration and the difference was not significant $(\mathrm{p}=0.926)$.

Table 4. Incidence of vaginal and anal penetration among both male and female victims

\begin{tabular}{lll}
\hline \hline & Opinion & \multicolumn{2}{c}{ Total $(\mathbf{N}=183)$} \\
$\%(\mathbf{n})$ & $\mathbf{5 0 ( 9 2 )}$ \\
\hline Type of penetration & & $\mathbf{0 7}(\mathbf{1 2})$ \\
& Vaginal penetration & $\mathbf{2 8}(\mathbf{5 1})$ \\
& Anal penetration & $15(27)$ \\
\hline \hline
\end{tabular}

Five $(2.7 \%)$ had associated physical abuse as well. Regarding further referrals, $80 \% \quad(n=146)$ were referred to STD clinic and $84 \%(n=154)$ were referred to the psychiatrist. In Puttalam Base Hospital, most of the CSA cases presented to the Judicial Medical Officer are admitted to the paediatric ward. Further, almost all cases, the child was examined by pediatrician. In $20 \%(\mathrm{n}=37)$, an Institutional case conference (ICC) was organized, and it was conducted especially for the custody issues of the child. Pediatricians involved in all ICCs. However, ICCs were not organized in $32 \%(n=58)$ of cases with anal penetration. Further, $20 \%(n=24)$ of victims with hymenal tears and $18 \%(n=8)$ with no hymenal tears were considered for ICC $(\mathrm{p}=0.800)$.

\section{Discussion}

Puttalam District is situated in the north western province about 130 kilometers north of Colombo, the capital of Sri Lanka. ${ }^{[4]}$ When Muslim victims were considered, though $18.8 \%$ of the population in Puttalam District is Muslims (Sri Lankan moor) ${ }^{[5]}$, the incidence of Muslim victims in this research was low as $9 \%$. Further, the urban areas of the Puttalam district are dominated by Muslims (95\%) while Buddhists and Christians dominate the rural areas and, the Hindus are the minority.[2]Since most of the victims (90\%) were Sinhalese, the incidence of child sexual abuse was more in rural areas than the Muslim dominant urban areas. However, the place of abuse; at home or outside 
was not significantly associated with urban or rural living ( $p>0.05)$.

When the sex of the victims of child sexual abuse was considered, as expected, most of the victims (92\%) were females. Similarly, a study done from 2011-2013 in Colombo, Sri Lanka also showed that the females are at high risk of being sexually abused. ${ }^{[6]}$

When the age of the victim was considered, $77 \%$ of them belonged to $11-18$ years. Similarly, a study done in Sri Lanka (2014) also showed that the females above 10 years are commonly being sexually abused. [6] According to Purewal (1995), child sexual abuse statistics revealed an estimated $50 \%$ of girls being sexually abused before the age of 15 years ${ }^{[7]}$ whereas, in this study, $90 \%$ of children were abused before the age of 15 years.

When the abuser is considered, it was revealed that all the abusers were males. Similarly, in a study performed in Spain, offenders were mainly males $(87.6 \%) \cdot{ }^{[8]}$ When the relationship of the offender to the victim was considered, it was revealed that the most potential abusers are 'Known-Non-relatives'. Similarly, in a study conducted in Spain, the offenders were mostly known to the victims such as friends, neighbors, or schoolmates. ${ }^{[8]}$ Moreover, a study done in Colombo, Sri Lanka (2014) also showed that the majority of perpetrators were known non-relatives such as boyfriends or others. ${ }^{[6]}$

When the place of the incident was considered, incidents have taken place equally at home (53\%) and outside home (47\%). Further, as expected, at home, there was significant risk of being abused by relatives $(\mathrm{p}<0.05)$.

When the simultaneous other types of abuses were considered, study showed that almost negligible number of victims (3\%) had been subjected to physical abuse.

When the hymen type of the victims was considered, the most common type was cresentic. In a study done in Galveston, USA (1992), a cresentic hymen was the most common $(51 \%)$ in girls older than 2 years and less than 7 years. ${ }^{[9]}$ In this study, all the victims were more than 3 years and most common type of hymen was cresentic hymen (51\%) and less than 10 years of age girls had higher chance to possess a cresentic hymen $(\mathrm{p}<0.05)$.

When the high risk age for penetrative sexual assaults was considered, it was revealed that more than 10 years old girl victims had a higher risk of getting hymenal tears due to penetrative intercourse $(\mathrm{p}<0.05)$. In a study performed in Colombo, Sri Lanka (2014), there was a higher chance of being subjected to penetrative intercourse such as anal, oral and vaginal for victims above 10 years of age. ${ }^{[6]}$

Regarding anal intercourse, in the current study, 7\% showed evidence of only anal penetration and $28 \%$ showed both genital and anal penetration. Moreover, one third of both males and female victims had evidence of anal penetration ( $p>0.05)$ and it showed that there was no sexual preference for anal abuse.

When management of the victims of child sexual abuse is considered, it was revealed that the victims are being referred to other specialists or units and case conferences are being organized for psycho-social management and welfare. Child maltreatment is a global problem with serious life-long physical and psychological or psychiatric outcomes due to its high prevalence of short-term and long-term consequences. ${ }^{[3]}$ Therefore, these victims should be managed holistically, considering the victim as a member of a family. In this research, it was found that the number of referrals such as to the psychiatrist and STD clinic had been increased more than $80 \%$. However, none had been given STD prophylaxis.

In this study, 69\% $(\mathrm{n}=127)$ had studied up to $11^{\text {th }}$ standard and the education should be continued further even after the incident. Unfortunately, following similar sexual victimization, some victims are removed from the schools they were attending. When such issue erupts, help of the education department should be sought.

In this study, it was shown that more than $80 \%$ victims were referred to STD clinic and the consultant psychiatrist. In the future, the management process of child sexual abuse should be further improved up to multidisciplinary centres, counseling and victim support. ${ }^{[10]}$ Moreover, organization of institutional case conference (ICC) for the children affected with CSA is an important step for the future development of such multidisciplinary centres. In this research, it was revealed that one fifth of cases were subjected to ICC. However, presence or absence of hymenal tears had no significant influence on the organization of ICC $(p<0.05)$ because the main indications for the organization of case conferences were the issues of the future custody of the child than type or severity of injuries. 


\section{Conclusions}

Child sexual abuse (CSA) less frequently associated with physical abuse. Majority of incidents that occurred at home were committed by male relatives and the vulnerable gender was female. Known nonrelatives are the most potential abusers. Girls more than 10 years of age are the most vulnerable. Mere presence of injuries were not indications for institutional case conference. However, the follow-up reports of psycho-social managements were not available in all cases. However, none had been given STI prophylaxis and that should be considered for inclusion in the national guideline of management of CSA.

\section{References}

1. Vadysinghe AN, Senasinghe DPP, Attygalle U, Abeysekara AMG, Gunasena MDP, Ratnayake RMUC, Ilangarathna Banda YMG. An analytical study on socio-demographic and medico-legal factors of victims of sexual assault from the central and Sabaragamuwa provinces in Sri Lanka. Sri Lanka Journal of Forensic Medicine, Science \& Law. 2015; 6 (1):12-20.

2. Rapes surge in Sri Lanka amid weak laws. 2014. http://womenandmedia.org/rapes-surge-in-srilanka-amid-weak-laws/ (accessed on 14.01.2017).

3. Ferrara P, Guadagno C, Sbordone A, et al. Child abuse and neglect: A review of the literature. CurrPediatr Rev. 2016. [Epub ahead of print] (accessed on 12.10.2016)

4. Puttalam District. https://en. wikipedia .org/wiki /Puttalam_District (accessed on 12.10.2016)
5. Population and housing senses of Sri Lanka, Government $\quad 2001$. www.statistics.gov.lk/.../p7\%20population\%20a nd\%20Housing\%20Text-11-12-06.pd. (accessed on 12.10.2016)

6. Vidanapathirana M. Child Sexual Abuse; a Medico-Legal Analysis. International Journal of Medical Toxicology and Forensic Medicine. 2014;4(3): 91-97.

7. Purewal J. Sexual violence and the girl child. Soc Change. 1995 Jun-Sep;25(2-3):154-60.

8. Pereda N, Abad J, Guilera G. Lifetime Prevalence and Characteristics of Child Sexual Victimization in a Community Sample of Spanish Adolescents. J Child SexAbus. 2016;25(2):142-58. doi: 10.1080/10538712.2016.1123791.

9. Berenson AB, Heger AH, Hayes JM, Bailey RK, Emans SJ. Appearance of the hymen in pre pubertal girls. Pediatrics. 1992 Mar; 89(3):38794.

10. Vidanapathirana M, Tennakoon A, Amararatne RRGS, Gunawardene S, Rathnaweera RHAI, Ratnayake L. Comparison of patterns of sexual assault among male victims during and after civil strife in Sri Lanka. Medico-Legal Journal of Sri Lanka. 2015; 3(2): 9-15. 